\title{
Ayudas económicas municipales derivadas de la pandemia
}

\author{
Begoña SESMA SÁNCHEZ \\ Catedrática de Derecho Financiero y Tributario \\ Universidad de Oviedo
}

\begin{abstract}
RESUMEN
Las entidades locales han ejercido ampliamente su potestad subvencional desde la declaración del primer estado de alarma a través del Real Decreto 463/2020 en dos grandes ámbitos: la asistencia y ayuda social en situaciones de emergencia —competencia propia de las entidades locales - y la protección de actividades y sectores económicos especialmente afectados por la crisis (hostelería, comercio, turismo), competencia municipal más dudosa. En este área, dado que el Estado y las Comunidades Autónomas han afrontado más tardiamente sus propias líneas subvencionales (a partir del último trimestre del 2020), han sido las entidades locales quienes primariamente se han volcado en atender estas situaciones. Y junto a las subvenciones directas dirigidas a sostener las pérdidas de ingresos por la paralización de la actividad o a compensar gastos asociados a las medidas de protección sanitaria (adecuación de establecimientos, terrazas, adquisición de material sanitario), se han articulado también subvenciones dirigidas a compensar el pago de tributos locales. La tramitación procedimental de las subvenciones por las entidades locales se ha visto igualmente afectada por la crisis sanitaria. En este punto, la ampliación de los plazos para la ejecución, justificación y comprobación de la actividad subvencionada, al amparo del art. 54 del Real Decreto-ley 11/2020, de 31 de marzo, por el que se adoptan medidas urgentes complementarias en el ámbito social y económico para hacer frente a la covid-19, ha sido la singularidad procedimental más relevante. Junto a ella se ha recurrido a otras prácticas como la flexibilización y agilización de trámites, la exoneración de la acreditación de ciertos requisitos y garantías o el pago anticipado del importe total de la subvención en determinados supuestos.
\end{abstract}

Palabras clave: subvenciones; ayudas; entidades locales; covid-19.

\begin{abstract}
Since the declaration of the first state of emergency declared by $R D 463 / 2020$, local authorities have exercised their subsidy powers to a large extent in two main areas: social
\end{abstract}


assistance and aid in emergency situations -own competence of local authorities - and the protection of economic activities and sectors particularly affected by the crisis (hotels, commerce, tourism), a more dubious municipal competence. In this case, given that the State and the Autonomous Regions have been later to provide these subsidies (from the last quarter of 2020), it has been the local authorities who have been primarily involved in dealing with these situations. In addition to direct subsidies aimed at sustaining losses of income due to the stoppage of activity or compensating for expenses associated with health protection measures (adaptation of establishments, terraces, purchase of sanitary material), subsidies have also been provided to compensate for the payment of local taxes. The procedural processing of subsidies by local authorities has also been affected by the health crisis. Here, the extension of the deadlines for the execution, justification and verification of the subsidised activity, under article 54 of RD 11/2020 of 31 March, adopting urgent complementary measures in the social and economic sphere to address the covid-19, was the most significant procedural singularity. In addition to this, other practices have been used, such as the flexibility and streamlining of procedures, the exemption from the accreditation of certain requirements and guarantees or the advance payment of the total amount of the subsidy in certain cases.

Keywords: subsidies; grants; local authorities; covid-19.

SUMARIO: I. LA ACTIVIDAD SUBVENCIONAL DE LAS ENTIDADES LOCALES: ASPECTOS GENERALES.-II. EL ESTABLECIMIENTO Y CONCESIÓN DE SUBVENCIONES POR LAS ENTIDADES LOCALES EN EL CONTEXTO DE LA COVID-19: 1. Breve referencia al contexto presupuestario. 2. Ámbitos materiales y competenciales de la actividad subvencional vinculada a la covid-19: 2.1. Subvenciones y ayudas de emergencia social. 2.2. Actividades económicas y profesionales especialmente afectadas por la crisis sanitaria.-III. INCIDENCIA DE LA COVID-19 EN EL ÁMBITO PROCEDIMENTAL SUBVENCIONAL DE LAS ENTIDADES LOCALES.

\section{LA ACTIVIDAD SUBVENCIONAL DE LAS ENTIDADES LOCALES: ASPECTOS GENERALES}

Las crisis económicas, y la sanitaria actual que vivimos con motivo de la covid-19 está teniendo un impacto brutal en la actividad económica, tradicionalmente se han combatido con subvenciones y ayudas ${ }^{1}$. No solo con estos recursos, desde luego, pero sí es notorio el incremento de gasto público social de todo tipo para múltiples sectores y articulado de muy diversas formas (avales públicos, prestaciones temporales de empleo, beneficios fiscales, aplazamientos de pago, moratorias concursales, rebajas de

1 Así sucedió con la anterior crisis económica iniciada a mediados de 2008 como analizó muy certeramente G. FERNÁNDEZ FARRERES, «Subvenciones y ayudas económicas en tiempos de crisis», en J. R. FueNTES I GASÓ, J. GIFREU I FONT y L. CASADO CASADO (coords.), Estructuras administrativas y racionalización del gasto público. Problemas actuales de la expropiación forzosa. La reforma de los entes locales en Italia en el contexto de la crisis económica: actas del VII Congreso de la Asociación Española de Profesores de Derecho Administrativo, Tarragona, 10 y 11 de febrero de 2012, pp. 117 y ss. 
arrendamientos...). El recurso a las subvenciones públicas ha sido y está siendo, sin lugar a dudas, una de las fórmulas empleadas por todos los niveles administrativos, amén de los diversos y cuantiosos fondos e instrumentos de recuperación aprobados por la Unión Europea que previsiblemente se articularán, en parte, también a través de subvenciones. La casuística es inmensa: subvenciones de carácter social y asistencial para combatir situaciones de emergencia, ayudas directas al comercio, la hostelería, el turismo, la industria, los sectores culturales, el fomento del teletrabajo, la digitalización, la compra de materiales de protección, para el pago de impuestos, bonificaciones y ayudas al mantenimiento del empleo, compensaciones económico-financieras a concesionarios y contratistas públicos... Las entidades locales no han permanecido ajenas a esta práctica de subvenir con fondos públicos a las familias y sectores más afectados por la paralización de la actividad económica, continuada en ocasiones e intermitente en otras, y desigual territorialmente, que ha supuesto la pandemia internacional de covid-19.

Antes de analizar la actividad subvencional de las entidades locales desde la declaración del (primer) estado de alarma el 14 de marzo de 2020 con motivo de la crisis sanitaria de covid-19 (Real Decreto 463/2020, de 14 de marzo), conviene exponer brevemente el contexto general en el que las entidades locales establecen, conceden y gestionan subvenciones públicas ${ }^{2}$.

La potestad de estas administraciones para conceder subvenciones está reconocida explícitamente en el art. 3.1.b) de la Ley 38/2003, de 17 de noviembre, General de Subvenciones (en adelante LGS), que cita a «b) las entidades que integran la Administración local» como Administraciones públicas que quedan sometidas a dicha norma. La sujeción a la LGS es especialmente intensa en el caso de las entidades locales porque esta norma, más que una Ley "general» de subvenciones —en tanto que muchas otras «ayudas» públicas escapan de su ámbito objetivo de aplicación- es, sobre todo, una ley esencialmente básica. Así lo dispone su DF 1. a señalando que la LGS se dicta al amparo de lo dispuesto en los apartados 1.13, 14 y 18 del art. 149 de la Constitución, enumerando a continuación los preceptos de la misma que tienen carácter básico. No procede ahora analizar el excesivo carácter básico de alguno de los preceptos de esta ley, algunos de los cuales han merecido reproche constitucional ${ }^{3}$, pero sí cabe advertir tres observaciones a mi juicio especialmente relevantes con relación a la aplicación de la LGS a las Administraciones locales.

La primera es que la aplicación de esta normativa básica estatal debe conciliarse en ocasiones con la aplicación de normativa autonómica que, en aquellos extremos no

\footnotetext{
2 Una visión general en F. M. BASTARDO YUSTOS, El régimen jurídico de las subvenciones en el ámbito local, Wolters Kluver, 2017.

3 Vid., en particular, las SSTC 70/2016, de 14 de abril; 206/2013, de 5 de diciembre; 152/2014, de 25 de septiembre, y 33/2018, de 12 de abril. Al respecto vid., entre otros, I. POMED SÁNCHEZ, «Los ámbitos territorial y temporal de la aplicación de la ley», en G. Fernández Farreres (dir.), Comentarios a la Ley General de Subvenciones, Madrid, 2005, pp. 67 y ss., y A. PAlOMAR OlMEDA, «Distribución constitucional de competencias en la materia. El concepto de poder de gasto subvencional en la doctrina del Tribunal Constitucional», en VVAA, Derecho de las subvenciones y ayudas públicas, Aranzadi, 2018, pp. 111 y ss.
} 
básicos, pueden afectar la potestad subvencional de sus respectivas entidades locales. Tal situación está expresamente prevista en el apartado 2 de la citada DF $1 .^{\text {a }}$ de la LGS conforme al cual: «Las restantes disposiciones de esta ley resultarán únicamente de aplicación en el ámbito de la Administración General del Estado, de las entidades que integran la Administración local y de los organismos y demás entidades de derecho público con personalidad jurídica propia vinculadas o dependientes de las mismas [...]. No obstante, cuando las Comunidades Autónomas hubieran asumido competencias en materia de régimen local, la ley se aplicará a las entidades que integran la Administración local en el ámbito territorial de las referidas Comunidades Autónomas, de acuerdo con lo establecido en el apartado 1 de esta disposición». Así pues, el parámetro normativo para que las entidades locales desarrollen su actividad subvencional puede consistir, bien en la aplicación íntegra de la normativa básica estatal, bien en la aplicación de los preceptos básicos de la misma complementados con la respectiva normativa autonómica en aquellos casos en los que la Comunidad Autónoma hubiera asumido competencias en materia de régimen local y así lo hubiera establecido expresamente ${ }^{4}$.

La segunda observación general que procede señalar es que, desde su origen, se ha evidenciado que la aplicación de la LGS es extragrande respecto de una gran mayoría de entidades locales. Muchas de sus previsiones resultan desproporcionadas referidas al ámbito local. La LGS se elaboró desde la perspectiva estatal, aunque con vocación de normativa básica para todas las Administraciones públicas, pero la actividad subvencional municipal no fue un parámetro tenido en cuenta durante su elaboración. Prueba de ello es la previsión de que habría un futuro desarrollo reglamentario de la LGS adaptado a las entidades locales según se recoge en la DA 14 de la Ley al disponer que «los procedimientos regulados en esta ley se adaptarán reglamentariamente a las condiciones de organización y funcionamiento de las corporaciones locales». Huelga decir que dicho desarrollo reglamentario hasta el momento no se ha efectuado de modo que, en la práctica, las entidades locales bien en una ordenanza general o específica de subvenciones o bien en el marco de las bases de ejecución del presupuesto adaptan procedimentalmente la aplicación de la LGS a su ámbito territorial ${ }^{5}$.

Por otro lado, previsiones como la exigencia de una planificación estratégica de subvenciones (art. 8 LGS) resultan exageradas para municipios que solo tienen, potencial-

${ }^{4}$ Así lo han previsto Comunidades como Cantabria (Ley 10/2006, de 17 de julio, de subvenciones de Cantabria) o Galicia (Ley 9/2007, de 13 de junio, de subvenciones de Galicia). Sin embargo, no contemplan esta posibilidad la Ley de Subvenciones de la Comunidad de Madrid (Ley 2/1995, de 8 de marzo, de subvenciones de la Comunidad de Madrid) ni la normativa balear (Decreto Legislativo 2/2005, de 28 de diciembre, por el que se aprueba el texto refundido de la Ley de subvenciones). En otros casos, el marco jurídico aplicable resulta de la yuxtaposición de normativa básica estatal y normativa autonómica propia (caso de Cataluña, p. ej., donde sus entidades locales aplican la normativa básica estatal de la LGS y normativa autonómica propia en otros ámbitos).

5 Al respecto vid. M. GarCÉs SAnAgustín y M. J. Monzón MaYo, «Ámbito subjetivo de la Ley general de subvenciones. Capacidad jurídica para el establecimiento y otorgamiento de subvenciones», en VVAA, Derecho de las subvenciones y Ayudas públicas, Aranzadi, Pamplona, 2018, pp. 12 y ss. 
mente, una línea de subvenciones para beneficiarios perfectamente identificados (piénsese en las subvenciones de un pequeño municipio para actividades culturales, sociales, festivas o algún tipo de ayuda de contenido social o asistencial). Por este motivo, no puede extrañar que en el ámbito local, frente a la concurrencia competitiva como forma ordinaria de concesión de subvenciones (art. 22 LGS), se practique con frecuencia la concesión directa, amparada en muchas ocasiones en convenios de colaboración o en simples resoluciones singulares de concesión directa al amparo de asignaciones nominativas en los respectivos presupuestos. De hecho, la concesión directa de subvenciones podríamos decir que es directamente proporcional al tamaño de la entidad local: cuanto más pequeña es esta, mayor utilización de la concesión directa, vía convencional o simplemente a través de un acto o resolución.

Otro de los ámbitos de la LGS que resulta desproporcionado para muchas entidades locales es el procedimiento y régimen de control financiero que contempla la LGS, máxime teniendo en cuenta que muchas entidades locales a día de hoy ni siquiera practican control financiero en su actividad ordinaria de gasto. La LGS es muy consciente de ello y de ahí la previsión contenida en la DA 2. ${ }^{a}$ de la LGS al contemplar la posibilidad de que las entidades locales puedan recabar el auxilio de la Intervención General de la Administración del Estado para desarrollar el control financiero y al habilitarles asimismo para la «contratación de la colaboración para la realización de controles financieros de subvenciones con auditores privados» en la DA $4 .^{\text {a }}$ de la LGS.

En fin, solo ocasionalmente la LGS se «acuerda» de las entidades locales en cuestiones puntuales escasamente relevantes o con referencias genéricas, como la previsión contenida en el art. 10.4 de la ley cuando señala que «la competencia para conceder subvenciones en las corporaciones locales corresponde a los órganos que tengan atribuidas tales funciones en la legislación de régimen local»; cuando se prevé que «las bases reguladoras de las subvenciones de las corporaciones locales se deberán aprobar en el marco de las bases de ejecución del presupuesto, a través de una ordenanza general de subvenciones o mediante una ordenanza específica para las distintas modalidades de subvenciones» (art. 17.2 LGS); o cuando se establece que será «la intervención u órgano que designe la propia entidad local» quien deba suministrar información a la Base de Datos Nacional de Subvenciones [art. 20.4.c) LGS].

En tercer lugar procede señalar que, a diferencia de otras administraciones, las locales no solo conceden subvenciones, sino que son usualmente beneficiarias de subvenciones europeas, autonómicas y locales hasta el punto de que el Texto Refundido de la Ley Reguladora de las Haciendas Locales contempla las subvenciones como ingreso ordinario de las entidades locales [art. 2.1.d) $]^{6}$. Desde el punto de vista presupuestario,

${ }^{6} \mathrm{Al}$ respecto vid., el clásico trabajo de C. LOZANO SERRANO, Las subvenciones del estado a los municipios, Instituto de Estudios de Administración Local, Madrid, 1981. Por mi parte, hace ya tiempo señalaba, y considero que la reflexión sigue estando vigente en la actualidad, que «si las subvenciones responden a una política de fomento determinada y ocasional, no debieran figurar como un ingreso ordinario y permanente de la hacienda local. El art. 40 restringe indebidamente las posibles finalidades que puedan tener las subvenciones obtenidas 
resulta problemático en ocasiones computar la expectativa de contar con un ingreso subvencional ${ }^{7}$. Un ejemplo actual de lo dicho es la notoria incertidumbre respecto de las cuantías que puedan recibir las entidades locales de la financiación europea articulada a través de los distintos instrumentos y fondos de recuperación NextGenerationE $U^{8}$. Toda una incógnita.

En muchas de las ocasiones en las que las entidades locales resultan beneficiarias de «subvenciones» resulta difícil diferenciar si estamos ante una transferencia o aportación dineraria o una verdadera subvención y, cuando lo es, concurre el problema de la posible afectación al principio de autonomía local (art. 9.7 de la Carta Europea de la Autonomía Local, de 15 de octubre de 1985, ratificada por España el 20 de enero de 1988) en la medida en que la Administración concedente (estatal o autonómica) puede interferir, vía subvenciones, en el ejercicio de competencias que son propias de la entidad local ${ }^{9}$. En tales supuestos, la posición de la entidad local no se diferencia

por las entidades locales y no aporta nada al régimen general de la figura [...]. Entiendo, por tanto, que, con independencia del peso histórico que tradicionalmente han tenido estos entes como beneficiarios de subvenciones, es superflua su mención como ingreso en la Ley de Haciendas Locales, salvo si lo que se quiere es destacar que tales entes pueden recibir participaciones en los ingresos del Estado o algún otro tipo de asignaciones de la Administración central, en cuyo caso son estos términos los que deberían haberse utilizado. Si igualmente se quiere destacar que excepcionalmente las entidades locales podrán recibir subvenciones, en nuestra opinión, el precepto debería redactarse de otro modo [...] sin necesidad de vincular la finalidad de la figura exclusivamente a las "obras y servicios" ni recordar, innecesariamente, las facultades de control de la administración concedente, sino simplemente estableciendo su remisión a las normas que configuran el régimen general de la figura», vid. B. SeSMA SÁnCHEZ, Las subvenciones públicas, Lex Nova, Valladolid, 1998, pp. 199 y ss.

7 Así, la DA 8. a de la LGS dispone que «las subvenciones que integran el Programa de cooperación económica del Estado a las inversiones de las entidades locales, de la misma forma que las subvenciones que integran planes o instrumentos similares que tengan por objeto llevar a cabo funciones de asistencia y cooperación municipal se regirán por su normativa específica, resultan de aplicación supletoria las disposiciones de esta ley».

Debe advertirse, por otra parte, que el art. 173.6 LRHL condiciona la disponibilidad de los créditos presupuestarios vinculados a subvenciones y otro tipo de ayudas que reciba la entidad local a «la existencia de documentos fehacientes que acrediten compromisos firmes de aportación, en caso de ayudas, subvenciones, donaciones u otras formas de cesión de recursos por terceros tenidos en cuenta en las previsiones iniciales del presupuesto a efecto de su nivelación y hasta el importe previsto en los estados de ingresos en orden a la afectación de dichos recursos en la forma prevista por la ley o, en su caso, a las finalidades específicas de las aportaciones a realizar».

8 Al margen de las demandas políticas planteadas a través de la FEMP para que las entidades locales reciban un determinado porcentaje de los fondos europeos, la mera expectativa genera una incertidumbre presupuestaria notable en el momento actual. Al respecto vid. J. M. MARTínEZ FernáNDEZ, «Las entidades locales ante la gestión de los fondos comunitarios para la superación de la covid y la modernización de la sostenibilidad económica», Revista de Estudios Locales, núm. 239, 2021.

9 El art. 2.2 LGS declara «no comprendidas» en su ámbito de aplicación a las «aportaciones entre las diferentes Administraciones públicas, para financiar globalmente la actividad de la Administración a la que vayan destinadas», exclusión que el art. 2.2 del Real Decreto 887/2006, de 21 de julio, por el que se aprueba el Reglamento de la Ley 38/2003, de 17 de noviembre, General de Subvenciones (en adelante RGS), precisa del siguiente modo: «Se entenderá por financiación global las aportaciones destinadas a financiar total o parcialmente, con carácter indiferenciado, la totalidad o un sector de la actividad de una Administración pública o de un organismo o entidad pública dependiente de esta». Al respecto vid. G. FERNÁNDEZ FARRERES, «Las entidades locales ante la actividad de fomento mediante subvenciones de las CCAA», Cuadernos de Derecho Lo- 
significativamente de la de un beneficiario privado, con sus respectivas obligaciones esenciales de ejecución de la actividad subvencionada, justificación, sometimiento a actuaciones de control y posibles reintegros, aunque habitualmente existen singularidades en su régimen de concesión y justificación. Así, aunque en ocasiones se supedita su otorgamiento al cumplimiento en plazo del deber de la entidad local de rendición de cuentas ante los órganos de control externo, con frecuencia se les exime, en cambio, del deber de acreditación de los requisitos ordinarios para ser un beneficiario de subvenciones (art. 13 LGS), lo que las libra en muchas ocasiones de aportar garantías cuando reciben pagos anticipados. Asimismo, la concesión, gestión y justificación de subvenciones otorgadas a entidades locales es mucho más flexible (p. ej., para reformular sus solicitudes, modificar los plazos de ejecución, simplificar las formas de justificación o aceptación de sus propios sistemas de «autocontrol» de las subvenciones que reciben...). Y, por supuesto, los expedientes de reintegro de subvenciones por entidades locales, y ya no digamos la imposición de sanciones teniendo en cuenta lo poco que se ejerce, en general, la potestad sancionadora en el ámbito subvencional, son escasamente frecuentes.

Por otro lado, tampoco es atípico que las entidades locales actúen como colaboradoras en la gestión de subvenciones europeas, estatales o autonómicas al amparo de la posibilidad que expresamente les reconoce los arts. 12.3 y 16.4 LGS, con algunas singularidades también en el ámbito de sus obligaciones de justificación.

En definitiva, el binomio subvenciones públicas y entidades locales lleva existiendo desde hace muchas décadas en nuestro panorama administrativo, ha estado muy

cal, núm. 21, Fundación Democracia y Gobierno Local, 2009, pp. 28 y ss.; B. SeSMA SÁnCHEZ, «Subvenciones autonómicas y entidades locales», Presupuesto y gasto público, núm. 89, 2017, pp. 51 y ss.

En este contexto, merece una cita la reciente STC 40/2021, de 18 de febrero, que resuelve un recurso de inconstitucionalidad interpuesto frente al Decreto-ley de la Junta de Castilla y León 6/2020, de 2 de julio, de medidas urgentes para incentivar las medidas de recuperación económica y social en el ámbito local. Esta norma, avalada por el Tribunal Constitucional, aparte de apreciar que concurrían circunstancias de «extraordinaria y urgente necesidad» ante una situación de "crisis sin precedentes» por la pandemia de covid-19, habilitaba la modificación del Fondo de Participación en los impuestos propios de la Comunidad y del Fondo Cooperación Económica General a los efectos de adelantar la percepción por las entidades locales de tales partidas para favorecer la recuperación económica y social y, aunque esa mayor financiación viniera acompañada de más condicionalidad y menos autonomía para la entidad local, el Tribunal Constitucional ha considerado que «exigir que las entidades locales destinen los recursos recibidos de la Comunidad Autónoma a inversiones, en lugar de sufragar operaciones corrientes o financieras, se ajusta al objetivo de impulsar la reactivación económica» y constituyen metas compartidas a nivel nacional, europeo y mundial y de una gran amplitud, que incluyen, a título de ejemplo, el poner fin a la pobreza; garantizar la disponibilidad de agua y energía asequible y sostenible; promover el crecimiento económico y el pleno empleo; impulsar la industria, la innovación y las infraestructuras; fomentar ciudades inclusivas, seguras, resilientes y sostenibles; luchar contra el cambio climático, etc. Es más, considera el Tribunal Constitucional que habilitar este fondo autonómico para que las entidades locales realicen inversiones, «favorecerá a las entidades locales a la hora de cumplir con la "regla de gasto" establecida en el art. 12 de la Ley Orgánica 2/2012, de 27 de abril, de Estabilidad Presupuestaria y Sostenibilidad Financiera, toda vez que, para su cálculo, no computa "la parte del gasto financiado con fondos finalistas procedentes de otras Administraciones públicas" (art. 12.2 de la Ley)». En definitiva, se legitima una subvención autonómica de la que se benefician entidades locales y que, aunque resulte condicionada, supondrá un mayor límite de gasto para afrontar la crisis de covid-19. 
presente en la configuración de las haciendas locales, tanto como beneficiarias o entidades colaboradoras de las subvenciones recibidas de otras administraciones o como sujetos concedentes de subvenciones vinculadas a sus servicios y actividades, si bien manifiesta singularidades en todos los casos que, a mi juicio, sin embargo, el marco jurídico general vigente (básicamente constituido por la LGS y su RGS, la LBRL y el LRHL, sin perjuicio de la normativa autonómica en su caso) no ha resuelto adecuadamente.

\section{EL ESTABLECIMIENTO Y CONCESIÓN DE SUBVENCIONES POR LAS ENTIDADES LOCALES EN EL CONTEXTO DE LA COVID-19}

\section{Breve referencia al contexto presupuestario}

Desde una perspectiva general, en términos presupuestarios, la irrupción de la covid-19 en las entidades locales ha traído consigo la necesidad inmediata de ajustar las previsiones de ingresos y gastos. En términos de ingresos, refiriéndonos en particular a los tributarios, el comportamiento de las entidades locales merece una valoración muy positiva porque no habiendo recibido ayuda financiera estatal (prometida) específica para afrontar las repercusiones de las mayores necesidades de gasto, y habiendo sido limitada la ayuda autonómica ${ }^{10}$, las entidades locales han sido proactivas, generosas e imaginativas. Dada su limitada capacidad para introducir beneficios fiscales, han acudido a diversas técnicas para alcanzar un resultado material similar. Así, han introducido bonificaciones fiscales, incluso retroactivas, en algunos impuestos locales (IBI, IAE); han acordado suspensiones temporales de la aplicación de ordenanzas fiscales, paralizando de facto la exacción de las cuotas tributarias; han reconocido (incluso de oficio, en algunos casos) devoluciones de tasas por servicios y actividades que no pudieron desarrollarse debido a las restricciones de movilidad, apertura y aforo de establecimientos y actividades; y, finalmente, han utilizado la concesión de subvenciones para el pago de impuestos locales, en algunos casos como subvenciones directas con esta única finalidad (técnica controvertida) y, en otros, incluyendo las cuotas tributarias de los tributos locales como gasto subvencionable junto a otros gastos corrientes. Asimismo, han perseguido flexibilizar y aligerar al máximo el pago de los tributos locales (principalmente de las tasas),

10 Solo ocasionalmente algunas Comunidades Autónomas han articulado líneas de subvenciones dirigidas a las entidades locales para hacer frente a diversos gastos relacionados con la crisis sanitaria. Así, Andalucía incrementó las ayudas directas dirigidas a municipios menores de 20.000 habitantes, a través de una mayor dotación de las cantidades recibidas por la participación en los tributos de la Comunidad Autónoma, vid. Decreto-ley 4/2021, de 23 de marzo, por el que se adoptan diversas medidas, con carácter urgente y extraordinario, como consecuencia de la situación ocasionada por el coronavirus (covid-19), y se modifican otras disposiciones normativas. También Castilla y León aprobó incrementos de las aportaciones autonómicas a entidades locales a través del Decreto-ley de la Junta de Castilla y León 6/2020, de 2 de julio, de medidas urgentes para incentivar las medidas de recuperación económica y social en el ámbito local. 
mediante aplazamientos y fraccionamientos con el objetivo, razonable y justificado, de procurar un cierto alivio fiscal a los contribuyentes más afectados por la crisis sanitaria ${ }^{11}$.

En términos de gasto público, las entidades locales han debido enfrentarse a las negociaciones del reequilibrio económico financiero de sus concesionarios, a contrataciones de urgencia y de emergencia, a gestiones sobrevenidas (p. ej., las vinculadas a la colaboración en la gestión del ingreso mínimo vital) y, en el ámbito que nos ocupa, a la necesidad de articular un apoyo subvencional en dos grandes ámbitos: la asistencia social en sentido amplio y la ayuda a los sectores económicos locales más afectados por las restricciones de apertura y aforo de establecimientos.

Sin duda, aunque el régimen de endeudamiento de las entidades locales no se ha modificado en este periodo, la suspensión de las reglas fiscales para las entidades locales desde el 20 de octubre de 2020, amparada en el art. 135.4 CE y de conformidad con lo previsto en el art. 11.3 LOEPSF, para los años 2020 y 2021 ha traído consigo una mayor flexibilidad en materia de gasto en tanto que los remanentes de tesorería pueden destinarse a otros fines distintos de las inversiones financieramente sostenibles y la amortización de deuda ${ }^{12}$.

\section{2. Ámbitos materiales y competenciales de la actividad subvencional vinculada a la covid-19}

Descartada legalmente la discrecionalidad o el «libre albedrío» en la concesión de subvenciones públicas, puesto que existe un régimen jurídico preceptivo de obligado cumplimiento para todos los sujetos habilitados para la concesión de estas ayudas y un elenco de principios generales que rigen su establecimiento y concesión (planificación, mínima distorsión en el mercado, publicidad, transparencia, concurrencia, objetividad y no discriminación, eficacia y eficiencia) ${ }^{13}$, resulta notorio que las entidades locales no pueden conceder subvenciones a quienes quieran (la LGS exige la acreditación de determinados requisitos para ser beneficiario) ni pueden subvencionar en ámbitos materiales ajenos a su nivel competencial. Esto es, ni pueden conceder subvenciones discrecionalmente sin justificación y al margen de parámetro procedimental alguno, ni pueden conceder subvenciones en ámbitos ajenos a sus competencias materiales.

11 Vid. B. Sesma SÁnCHEZ, "Incidencia del covid-19 en los tributos locales», Anuario de Gobierno Local, Fundación Democracia y Gobierno Local (2021), en prensa.

12 La suspensión de las reglas fiscales acordada por el Consejo de Ministros en su sesión de 6 de octubre de 2020, con efectos desde el 20 de octubre de 2020, ha supuesto, para las entidades locales, que el superávit no tenga que destinarse a amortizar deuda, aunque siga siendo posible realizar esa amortización si la entidad local así lo dispone. Esto es, la regla del art. 32 LOEPSF puede no aplicarse desde el momento en que se han suspendido las reglas fiscales y ello implica, asimismo, que tampoco es necesaria la regla de destinar el superávit a financiar inversiones financieramente sostenibles, pudiendo destinarse a otros gastos sociales en los términos y cuantías establecidos expresamente en el art. 3 del Real Decreto-ley 8/2020, de 17 de marzo, y en el art. 20 del Real Decreto-ley 11/2020, de 31 de marzo.

13 Vid. art. 8 LGS. 
La interrelación entre subvenciones y competencias materiales es un tema clásico de la potestad de gasto subvencional. Desde que el Tribunal Constitucional tuviera que analizar, en múltiples conflictos competenciales, la vinculación entre la potestad de gasto estatal y las competencias materiales a los efectos de determinar la constitucionalidad de subvenciones estatales que interferían en competencias autonómicas, constituye un principio básico ordenador de esta figura la necesidad de que la subvención establecida encaje en el ámbito competencial del sujeto que la convoca. Es de todos conocida la doctrina constitucional según la cual «la subvención no es un concepto que delimite competencias» (STC 13/1992, de 6 de febrero, FJ 4. ${ }^{\circ}$ ) de modo que "para la resolución de las controversias que se susciten respecto de la regulación y aplicación de las ayudas o subvenciones que puedan establecerse en las distintas áreas o segmentos de la acción pública hemos de partir de la distribución de competencias existente en la materia constitucional en la que proceda encuadrar las subvenciones de que se trate» (por todas, entre otras muchas, STC 139/2009, de 15 de junio).

En el ámbito local, el parámetro competencial de las entidades locales viene definido en la Ley 7/1985, de 2 de abril, Reguladora de las Bases del Régimen Local que, a su vez, no puede interpretarse sin considerar, de una parte la Ley 27/2013, de 27 de diciembre, de racionalización y sostenibilidad de la Administración local y, de otra, el LRHL, amén de las limitaciones que puedan derivarse de la normativa de estabilidad presupuestaria. Al amparo de este contexto competencial y presupuestario, es evidente que las entidades locales pueden establecer líneas de subvenciones en muy diversos ámbitos, pero siempre que tengan algún título competencial que directa o indirectamente les legitime para ello acreditando los requisitos que resulten exigibles en cada caso (situación económico-financiera, informes de no duplicidad y de sostenibilidad financiera, entre otros). Esto es, es necesario que dispongan de una competencia propia o «habilitada» que ampare su actuación municipal en un concreto ámbito. Es obvio que una entidad local no puede subvencionar, por ejemplo, a una compañía área para compensar sus pérdidas con motivo de la covid-19, pero sí puede subvencionar a los establecimientos de territorio para que adquieran equipos de protección sanitaria o adecúen sus establecimientos y terrazas para cumplir con las restricciones de aforo y distancia si se acreditan requisitos de salubridad pública.

Pues bien, en el contexto de la covid-19, se han potenciado especialmente las líneas de subvenciones vinculadas a la asistencia social, a la protección de las actividades económicas más afectadas por la paralización de la crisis sanitaria, así como a compensar las pérdidas de actividades culturales, sociales y deportivas.

\subsection{Subvenciones y ayudas de emergencia social}

A diferencia de la tensión estatal/autonómica en la ordenación de subvenciones vinculadas al (amplio e indeterminado) concepto de asistencia social, que es causa frecuente 
de problemas competenciales ${ }^{14}$, las entidades locales ejercitan sin esa "tensión» su potestad subvencional vinculada a la ayuda social, generalmente como complementaria de la estatal y autonómica porque, ciertamente, este es un ámbito donde ninguna administración se sustrae a la sensibilidad social y al rédito político electoral que supone la articulación de un gasto público social ${ }^{15}$ que, además, aun teniendo este perfil social o asistencial, encaja materialmente en el concepto de subvención según ha interpretado reiteradamente la IGAE ${ }^{16}$. Todo lo más, las entidades locales reivindican una compensación general para sufragar su actividad subvencional o compensar esta competencia. Esa compensación, prometida por el Estado, no ha llegado sin embargo a materializarse, pero sí ha existido apoyo financiero autonómico en algunos casos.

Pues bien, al margen del alcance material de la competencia municipal en materia de asistencia social, lo cierto es que en líneas generales «no hay objeción posible a estas ayudas». Como ha señalado VeLASCO CABALLERO, «las leyes autonómicas de servicios sociales ya contemplan la posible asistencia municipal, tanto la básica como la urgente. Además, el art. 26.1.c) LBRL expresamente se refiere, para los municipios de más de 20.000 habitantes, al servicio público obligatorio de "atención inmediata a personas en situación o riesgo de exclusión social”, lo que ha sido interpretado por la STC 41/2016, FJ 9. ${ }^{\circ}$, como un título competencial municipal (y, por tanto, no solo como una obligación de servicios)» ${ }^{17}$. Asimismo, cabe recordar las competencias de la alcaldía al amparo del art. 124.4.h) LBRL para «adoptar las medidas necesarias y adecuadas en casos de extraordinaria y urgente necesidad, dando cuenta inmediata al Pleno». Y, en todo caso,

14 Vid., a título de ejemplo, entre las últimas controversias, la resuelta por la STS de 1 de diciembre de 2020 (rec. núm. 281/2019), referida a la impugnación, por parte de la Cataluña, del Real Decreto 303/2019, de 26 de abril, por el que se regula la concesión directa de una subvención a Cruz Roja Española, Comisión Española de Ayuda al Refugiado y ACCEM, al considerar que el Estado había invadido su ámbito competencial en esta materia de ayudas a la inmigración y debían haberse territorializado los fondos previstos en dicha norma. La sentencia, por el contrario, analizando la competencia estatal en materia de asistencia social vinculada al fenómeno de la inmigración, aduce determinadas singularidades de la norma para justificar la regulación estatal de esta subvención directa, desestimando el recurso.

15 De hecho, los beneficiarios de estas ayudas, usualmente las reciben de todos los niveles territoriales (ingreso mínimo vital estatal y/o rentas básicas autonómicas, ayudas de vivienda autonómicas, ayudas sociales municipales de emergencia o primera necesidad).

${ }^{16} \mathrm{Vid}$. la opinión de la IGAE recogida en la respuesta 4.12 del dossier de preguntas frecuentes sobre la BDNS y el SNPS, conforme a la cual «las rentas sociales u otras figuras análogas creadas por las Comunidades Autónomas o por las entidades locales, que quedan fuera del Sistema de Seguridad Social aunque se deban coordinar con él (vid. art. 6 TRLGSS), exceden del ámbito de la excepción contemplada en el art. 2.4.a) LGS y deben considerarse subvenciones a los efectos de esta ley y, por tanto, su información debe ser incorporada en la BDNS, por aplicación directa de la LGS» considerando que el concepto de subvención también alcanza a las entregas dinerarias que se conceden con motivo de la «concurrencia de una situación» en supuestos en los que la ley establece que el interesado solo tiene que acreditar que cumple los requisitos y, a partir de esa condición, es cuando se le otorga la subvención sin necesidad de justificación posterior (vid. art. 30.7 LGS), disponible en https://www.oficinavirtual.pap.hacienda.gob.es/sitios/oficinavirtualles-ES/CatalogoSistemasInformacion/TESEOnet/ Documents/RPF\%20BDNS\%20FAQ\%20-\%20febrero\%202019.pdf.

17 Vid. F. Velasco Caballero, "Derecho local y covid-19», Revista Gallega de Administración Pública, núm. 59, 2020, pp. 248 y 249. 
de forma expresa, al amparo del Real Decreto-ley 8/2020, de 17 de marzo, de medidas urgentes extraordinarias para hacer frente al impacto económico y social de la covid-19, se habilitó a las entidades locales a realizar no solo gastos en inversiones (capítulo 6) de la política 23 «Servicios Sociales y Promoción Social», sino también, con carácter excepcional, a realizar gasto corriente destinado a las siguientes prestaciones (art. 1.2), todas ellas de claro contenido social o asistencial:

a) Reforzar los servicios de proximidad de carácter domiciliario para garantizar los cuidados, el apoyo, la vinculación al entorno, la seguridad y la alimentación, especialmente los dirigidos a personas mayores, con discapacidad o en situación de dependencia, compensando así el cierre de comedores, centros de día, centros ocupacionales y otros servicios similares, considerando el mayor riesgo que asumen estas personas en caso de contagio. Estos servicios comprenden la ayuda a domicilio en todas sus modalidades y cualquier otro de análoga naturaleza que se preste en el domicilio de la persona usuaria.

b) Incrementar y reforzar el funcionamiento de los dispositivos de teleasistencia domiciliaria de manera que incrementen el ritmo de contactos de verificación y la vigilancia de la población beneficiaria de dicho servicio.

c) Trasladar al ámbito domiciliario, cuando sea considerado necesario, los servicios de rehabilitación, terapia ocupacional, servicios de higiene, y otros similares, considerando la suspensión de atención diurna en centros.

d) Reforzar los dispositivos de atención a personas sin hogar, con el personal y medios materiales adecuados, asegurando que tanto ellas como quienes las atienden estén debidamente protegidas, y posibilitar la ampliación, tanto en el tiempo de estancia como en intensidad, de los mismos.

e) Reforzar las plantillas de centros de Servicios Sociales y centros residenciales en caso de que sea necesario realizar sustituciones por prevención, por contagio o por prestación de nuevos servicios o sobrecarga de la plantilla.

f) Adquisición de medios de prevención (EPI).

g) Ampliar la dotación de las partidas destinadas a garantizar ingresos suficientes a las familias, para asegurar la cobertura de sus necesidades básicas, ya sean estas de urgencia o de inserción.

h) Reforzar, con servicios y dispositivos adecuados, los servicios de respiro a personas cuidadoras y las medidas de conciliación para aquellas familias (especialmente monomarentales y monoparentales) que cuenten con bajos ingresos y necesiten acudir a su centro de trabajo o salir de su domicilio por razones justificadas y/o urgentes.

i) Otras medidas que las Comunidades Autónomas, en colaboración con los Servicios Sociales de las entidades locales, consideren imprescindibles y urgentes para atender a personas especialmente vulnerables con motivo de esta crisis, y sean debidamente justificadas.

En este amplio censo de gastos sociales, se articularon diversas líneas de subvenciones por las entidades locales, dirigidas principalmente a personas físicas, familias, autónomos y pequeñas y medianas empresas, todas ellas amparadas en un contexto de clara emergencia social o asistencial: ayudas para cubrir gastos de alimentación e higiene 
para beneficiarios perceptores de rentas básicas, ayudas de comedor y libros de texto - aun habiéndose paralizado la actividad escolar presencial-, ayudas para la atención de personas en los domicilios, ayudas sociosanitarias de diversa índole, para familias vulnerables destinadas al pago de suministros básicos (agua, luz, gas, etc.).

Ahora bien, a mi juicio, la actividad subvencional de las entidades locales en materia de asistencia social plantea la cuestión de medir su eficiencia pues en una gran mayoría de supuestos hablamos de importes mínimos (de 30 euros para la compra de libros de texto, de 50 euros por una situación de emergencia social, 20 euros para desplazamientos por motivos de estudio, 60 euros de ayudas de comedor escolar...) y, sin embargo, lo cierto es que se establecen y tramitan como cualquier otra subvención con una elevada carga de gestión administrativa y coste, incluso, para sus solicitantes. No parece que la aprobación de bases, convocatorias, fiscalización de los expedientes, publicidad, tramitación de solicitudes, examen de la documentación justificativa y concesión "compensen» el gasto de gestión de muchas de estas subvenciones que, en algunos casos, a mi juicio, se canalizan mejor en términos de eficiencia y economía, a través de convenios de colaboración con otro tipo de entidades (Cruz Roja, Cáritas, fundaciones y asociaciones vinculadas a servicios sociales, escuelas-hogar...).

\subsection{Actividades económicas y profesionales especialmente afectadas por la crisis sanitaria}

A partir de la declaración del estado de alarma el 14 de marzo de 2020, un análisis de los datos recogidos en la BDNS revela que las primeras líneas de subvenciones establecidas por las entidades locales se destinaron a establecimientos comerciales, turísticos y de servicios afectados por el cierre inmediato de sus establecimientos y de sus actividades. En estos casos, la competencia municipal subyacente no es tan clara como en el caso de subvenciones de carácter social en situaciones de emergencia. De hecho, un análisis individualizado del alcance de las competencias materiales en estos sectores arrojaría muchas dudas al respecto. Por ejemplo, en materia de comercio, las competencias de las entidades locales se limitan al ámbito de la venta ambulante, siendo habitualmente competencia autonómica la regulación de la actividad comercial minorista, sin perjuicio de la colaboración entre ambos niveles administrativos. Lo mismo cabría decir de las competencias en materia de turismo y hostelería, más allá de intervenciones genéricas de promoción. ¿¿Hay título competencial suficiente para que las entidades locales habilitaran subvenciones a autónomos, hosteleros y comerciantes? Ciertamente, aunque se han planteado dudas por las propias entidades locales al respecto, y la situación es muy dispar según la normativa autonómica aplicable al caso, lo cierto es que en líneas generales tales dudas no han impedido el establecimiento de subvenciones en estas áreas con base en interpretaciones extensivas de las competencias municipales ${ }^{18}$. Así, se han articulado al amparo de una interpretación

18 Vid., al respecto, las consultas sobre «la competencia municipal en colaboración con las Comunidades Autónomas en materia de comercio: ¿permite conceder subvenciones a autónomos, hosteleros y comerciantes con motivo de la crisis por coronavirus?», disponible en https://derecholocal.es/consultalcompetencia-municipal- 
expansiva de la competencia de emergencia social referida al tejido productivo con el objetivo de minimizar el impacto económico generado por el estado de alarma que ha provocado situaciones de emergencia social en ciertos sectores productivos [art. 25.2.e) LBRL], al amparo de competencias en materia de salubridad pública [art. 25.2.j) LBRL] respecto de subvenciones vinculadas a la compra de equipos de protección sanitarios (mascarillas, guantes, pantallas protectoras...) o gastos de acondicionamiento de los locales para estos fines, al amparo del título de intervención genérico del art. 25.1 LBRL que habilita al municipio a "promover actividades y prestar los servicios públicos que contribuyan a satisfacer las necesidades y aspiraciones de la comunidad vecinal en los términos previstos en este artículo», o bien al amparo de la competencia local en «asuntos de interés general» (art. 7.4 LBRL), que precisa del doble informe vinculante de sostenibilidad y no duplicidad $^{19}$. Esta línea subvencional municipal articulada mediante la concesión directa de ayudas a los sectores del comercio, hostelería y turismo, principalmente, no se ha cuestionado, además, desde la perspectiva de la duplicidad en tanto que no ha sido hasta el último trimestre de 2020 cuando tanto el Estado como las Comunidades Autónomas han articulado ayudas directas a los sectores económicos más afectados por la crisis sanitaria. Es más, aún en los supuestos en los que ya se había establecido esa otra ayuda supramunicipal, las entidades locales han continuado estableciendo subvenciones dirigidas a tales sectores como "complementarias» a otras adoptadas por otras administraciones.

En algunos casos se ha acudido a la concesión directa de subvenciones a autónomos y pymes de los sectores principalmente afectados (los menos), mientras que en otros se ha utilizado el régimen general de no (concurrencia no competitiva). Acudiendo a estímulos positivos, muchas entidades locales pusieron en marcha "planes» "avanza», «resiste», «contigo», «adelante», «impulsa» y denominaciones similares vinculadas bien a compensar el cierre de las actividades bien a la dinamización o reactivación de las mismas. En muchos casos, las subvenciones consistían en cantidades fijas o variables (en función del número de trabajadores y superficie, principalmente) destinadas a compensar las pérdidas de ingresos asociadas a la paralización de la actividad o a sufragar gastos corrientes asociados a las limitaciones impuestas por las autoridades sanitarias

de-colaboracion-con-la-ca-en-materia-de-comercio-permite-conceder-subvenciones-a-autonomos-hosteleros-y-comerciantes-con-motivo-de-la-crisis-por-coronavirus, sobre "posibilidad de concesión de subvenciones municipales a comercios, pymes y hosteleros con motivo de la crisis por coronavirus", disponible en https://derecholocal. es/consultalposibilidad-de-concesion-de-subvenciones-municipales-a-comercios-pymes-y-hosteleros-con-motivo-de-lacrisis-por-coronavirus, y sobre si "iPuede el ayuntamiento, con motivo del coronavirus, conceder subvenciones a Pymes y autonómos por el cierre de su actividad?», disponible en https://derecholocal.es/consulta/puede-el-ayuntamiento-con-motivo-de-la-crisis-por-coronavirus-conceder-subvenciones-a-pymes-y-autonomos-por-el-cierre-de-suactividad.

19 En la misma línea ha señalado F. Velasco CABALLERO, con relación al informe autonómico de no duplicidad que «puede no ser especialmente complejo en aquellas Comunidades Autónomas que han optado por una definición legal muy estricta de la duplicidad. En tales casos, cabe una ayuda municipal inmediata allí donde aún no se han aprobado ayudas autonómicas. E incluso cuando ya haya algún tipo de ayuda autonómica, siempre que las subvenciones municipales atiendan a factores objetivos locales, diferenciados de los que puedan tener otras ayudas autonómicas», vid. «Derecho local y covid-19», op. cit., p. 249. 
(adecuación de terrazas, adquisición de material sanitario...). Estas líneas de subvenciones fueron generalizadas en muchas entidades locales durante los dos grandes periodos de paralización de las actividades (marzo a junio y noviembre a enero). Sin embargo, la puesta en marcha de ayudas estatales y ayudas autonómicas para el mismo perfil de actividades hizo decaer desde febrero del presente año (2021) la actividad subvencional de los municipios en este ámbito. Así, un sector obviamente subvencionado durante esta época como la hostelería fue objeto de ayudas estatales no tanto por la vía de gasto, sino a través de reducciones fiscales y otros estímulos financieros (prórrogas de los ERTE, ajustes en el régimen de tributación de estimación objetiva y simplificado, líneas de financiación avaladas por el ICO, cómputo de las pérdidas y rebajas de alquileres...) ${ }^{20} \mathrm{y}$ de ayudas autonómicas directas — con financiación estatal en gran medida- desde el último trimestre de 2020. Por ello, en líneas generales, la actividad subvencional municipal dirigida al sector de la hostelería a partir de esta fecha ha sido menor y meramente complementaria de la estatal y autonómica.

La delimitación de los sectores y actividades económicas subvencionables, el importe de las cuantías, la flexibilización de la tramitación y la presión por aligerar la acreditación de determinados requisitos exigidos para acceder a estas ayudas (como la obligación de estar al corriente de obligaciones tributarias y con la Seguridad Social) han sido las cuestiones más controvertidas de estas líneas de ayudas que, por lo demás, han podido compatibilizarse entre sí. La casuística ha sido muy variada, desde bases reguladoras generales y convocatorias específicas reiteradas periódicamente en función de cómo iba evolucionando la pandemia en el respectivo entorno municipal o convocatorias singulares y abiertas en régimen de no concurrencia competitiva. Evidentemente, el impacto económico de las ayudas municipales destinadas a estos sectores ha sido mucho menor pero se ha complementado, en muchas ocasiones, con la rebaja de tributos locales, como la suspensión de la aplicación de las ordenanzas fiscales de aprovechamiento de dominio público por terrazas y mobiliario o de la exacción de las tasas de basuras, agua y saneamiento.

Resta por apuntar una última medida empleada por las entidades locales para aliviar el coste fiscal de los tributos locales respecto de ciertos contribuyentes y actividades especialmente perjudicados por la crisis sanitaria: la posibilidad de establecer una línea de subvenciones para el pago de tributos locales y ciertas tasas ante la imposibilidad o dificultad de establecer su exención o su bonificación. Varias entidades locales han hecho

20 Vid., a nivel estatal, principalmente, de una parte, el Real Decreto-ley 35/2020, de 22 de diciembre, de medidas urgentes de apoyo al sector turístico, la hostelería y el comercio y en materia tributaria. $\mathrm{Y}$, de otra, el Real Decreto-ley 5/2021, de 12 de marzo, de medidas extraordinarias de apoyo a la solvencia empresarial en respuesta a la pandemia de covid-19. Esta norma creó una nueva Línea Covid de ayudas directas a autónomos y empresas, para reducir el endeudamiento suscrito a partir de marzo de 2020, con una dotación total de 7.000 millones de euros, canalizada a través de las Comunidades Autónomas. Estas ayudas directas tendrán carácter finalista, empleándose para satisfacer la deuda y realizar pagos a proveedores y otros acreedores, financieros y no financieros, así como los costes fijos, por ejemplo, relativos al suministro de energía y al coste de cambio de potencia, incurridos por los autónomos y empresas considerados elegibles, primando la reducción del nominal de la deuda con aval público, siempre y cuando las deudas se hubieran devengado a partir de 1 de marzo de 2020 y procedieran de contratos anteriores a la entrada en vigor de este real decreto-ley. 
uso de esta vía especialmente para compensar el pago del IBI y de ciertas tasas y refiriendo la ayuda a contribuyentes/beneficiarios que se encontraran en una situación de vulnerabilidad social con motivo de la covid-19 (p. ej., por encontrarse en una situación de desempleo, en ERTE o ser perceptores de ayudas sociales o tratarse de sectores especialmente afectados como la hostelería) o, en el caso del IVTM, por tratarse de sectores especialmente afectados (empresas de transporte por viajeros y autoescuelas).

$\mathrm{Al}$ respecto, sin embargo, procede recordar que el Tribunal Supremo ha censurado esta práctica señalando que "partiendo del respeto a la autonomía local y a la posibilidad legal de que los ayuntamientos apliquen en las ordenanzas fiscales beneficios potestativos, estos se fijarán con respeto a las previsiones legales del TRLHL y de la Ley General Tributaria (arts. 9.1 y 12.2 TRLRHL), debiendo fijar las cuotas del IBI conforme a lo dispuesto legalmente (art. 15.2 TRLHL), lo que nos lleva a sentar que las reducciones que se realicen en las cuotas impositivas deberán regirse por las determinaciones legales (art. 71 TRLHL). En consecuencia, no cabe duda alguna que el Ayuntamiento (es un párrafo literal de una STS por eso se recoge en su literalidad) no respetó en la aprobación del art. 13.9 de la Ordenanza del IBI las previsiones del art. 74.2 TRLHL, ya que si pretendía evitar subidas excesivas o poner un límite a los posibles incrementos anuales de la cuota del IBI debió de acudir a las reducciones por bonificaciones potestativas, con su consiguiente régimen normativo, en lugar de utilizar el peculiar sistema de subvenciones, ajenas en su naturaleza jurídica y fines al ámbito fiscal, razón por la que resulta acertada la argumentación de la sentencia impugnada cuando afirma que el ayuntamiento carecía de competencia para incluir en la gestión del IBI una minoración de la cuota líquida no contemplada ni en la Ley General Tributaria ni en el TRLHL, insistiendo en que los beneficios fiscales no tienen carácter de subvenciones y se rigen por su normativa propia» (STS de 19 de mayo de 2014, rec. núm. 3775/2010).

Ciertamente se trata de una práctica criticable y cuestionable no solo porque emplea fraudulentamente la figura de la subvención para sufragar el coste de un tributo, en vez de servir al objetivo general de destinar los fondos al cumplimiento de objetivos, a la ejecución de proyectos, la realización de actividades, la adopción de un comportamiento singular o la concurrencia de una determinada situación que «tenga por objeto el fomento de una actividad de utilidad pública o interés social o de promoción de una finalidad pública» (art. 2.1 LGS). En tales supuestos, resulta obvio que la subvención no fomenta ni incentiva actividad alguna, sino que se emplea para compensar el deber (personal) de pagar un tributo. De este modo se pervierte también el principio de igualdad, capacidad económica y generalidad que fundamentan el sistema tributario habilitando, al margen de la ley, la disposición gratuita de fondos públicos para que solamente determinados contribuyentes vean compensada su carga tributaria. Al mismo tiempo, es una mala práctica que quiebra fraudulentamente el principio de reserva de ley en materia de exenciones y beneficios fiscales recogido, en el ámbito tributario local, en el citado art. 9.1 TRLRHL. Si la subvención se destina a sufragar deudas tributarias ya devengadas, también se infringe el requisito básico exigido a todos los beneficiarios de subvenciones de acreditar - antes de la concesión y en todo caso en el momento del pago- estar al corriente de sus obli- 
gaciones tributarias (y con la Seguridad Social), tal y como se establece en el art. 13.2.e) LGS, si bien habría un mínimo de margen de justificar la obligación de acreditación de estas obligaciones por razón de la «naturaleza» de la subvención. De hecho, como es sobradamente conocido, es habitual que la simple solicitud de subvenciones lleve aparejada la obtención de información tributaria por parte de la Administración concedente para habilitar una comprobación rápida del citado requisito.

Con todo, la «ingeniería jurídico-financiera» de algunas entidades locales les ha permitido diseñar, con carácter más amplio, líneas de ayudas destinadas a financiar gastos corrientes de determinados sectores de actividad entre los cuales, expresa o indirectamente, resultan subvencionables las cuotas tributarias de determinados tributos locales. Es cierto que el art. 31.8 LGS — precepto no básico- contempla la posibilidad de tributos subvencionables, esto es, que dentro del concepto de gastos subvencionables puedan incluirse cuotas tributarias al disponer que "los tributos son gasto subvencionable cuando el beneficiario de la subvención los abona efectivamente. En ningún caso se consideran gastos subvencionables los impuestos indirectos cuando sean susceptibles de recuperación o compensación ni los impuestos personales sobre la renta». Al amparo de esta regulación, las cuotas de todos los tributos locales, así como de las tasas, serían un gasto potencialmente subvencionable siempre que el beneficiario de la subvención «los abonara efectivamente», requisito que debe entenderse en el sentido, no tanto de que el tributo esté íntegramente pagado o satisfecho al tiempo de justificar la subvención (ya que se admite acreditar el cumplimiento de estar al corriente de las obligaciones tributarias cuando se ha solicitado el aplazamiento, fraccionamiento o compensación), sino de acreditar que ha sido el beneficiario quien ha soportado materialmente la carga tributaria no teniendo la posibilidad de recuperarlo o repercutirlo (caso, p. ej., del IVA, pero que también podría darse en el caso de tributos locales usualmente repercutidos como el IBI en los locales de negocio exigido a los arrendatarios). Ahora bien, que resulte admisible la aceptación de ciertos tributos como gastos subvencionables, nada tiene que ver con la práctica anteriormente expuesta, cuando la línea de subvenciones se establece única o principalmente para pagar cuotas tributarias (en todo o en parte) y así se publicita, de hecho, en las bases reguladoras o en la convocatoria. En estos supuestos, el «fraude» consiste en desvirtuar, de una parte, la figura de la subvención para objetivos y finalidades que no le son propias y, de otra, utilizar la subvención para introducir exenciones y bonificaciones de tributos no amparadas en la ley ${ }^{21}$.

\section{INCIDENCIA DE LA COVID-19 EN EL ÁMBITO PROCEDIMENTAL SUBVENCIONAL DE LAS ENTIDADES LOCALES}

Aunque el marco jurídico general de la ordenación de subvenciones (estatal, autonómico y local) no ha variado desde la declaración del primer estado de alarma el 14

21 Reproduzco aquí parcialmente las consideraciones que he formulado sobre esta práctica en un trabajo reciente, vid. B. SESMA SÁNCHEZ, «Incidencia del covid-19 en los tributos locales», op. cit. 
de marzo de 2020 — aunque sí se ha modificado puntualmente al objeto de flexibilizar la gestión, tramitación y control de las subvenciones que (exclusivamente) se articulen con cargo al Plan de Recuperación, Transformación y Resiliencia financiado a través de los diversos fondos e instrumentos financieros europeos conocidos como NextGenerationEU» al amparo del Real Decreto-ley 36/2020, de 30 de diciembre, por el que se aprueban medidas urgentes para la modernización de la Administración pública y para la ejecución del Plan de Recuperación, Transformación y Resiliencia- ${ }^{22}$, desde el punto de vista procedimental, el establecimiento y concesión de subvenciones por las entidades locales vinculadas a la covid-19 ha presentado algunas singularidades de índole procedimental que merecen destacarse.

Por una parte, en términos generales, a la vista de la paralización procedimental administrativa que impuso la DA 3..$^{a}$ del Real Decreto 463/2020, y que estuvo en vigor hasta el 1 de junio de 2020, en un primer momento pudo deducirse que la actividad subvencional municipal debía detenerse por completo ${ }^{23}$. Esto es, que ni la entidad local podía convocar nuevas subvenciones, ni resolver las convocatorias que estuvieran abiertas, ni comprobar justificaciones, practicar controles o exigir reintegros. Evidentemente, tal primaria deducción resultaba desproporcionada en un contexto económico y social en el que las administraciones no podrían paralizarse en términos absolutos, máxime cuando se trataba de ordenar actuaciones inmediata y directamente vinculadas a la crisis sanitaria. De hecho, los apartados 3 y 4 de la DA citada contemplaban la posibilidad de que el órgano competente pudiera acordar «mediante resolución motivada, las medidas de ordenación e instrucción estrictamente necesarias para evitar perjuicios graves en los derechos e intereses del interesado en el procedimiento y siempre que este manifieste su conformidad, o cuando el interesado manifieste su conformidad con que no se suspenda el plazo». Esto es, se contemplaron excepciones a la suspensión generalizada de procedimientos administrativos especialmente de aquellos «que vengan referidos a situaciones estrechamente vinculadas a los hechos justificativos del estado de alarma, o que sean indispensables para la protección del interés general o para el funcionamiento básico

22 En efecto, este controvertido real decreto-ley introduce modificaciones singulares y específicas para la gestión, tramitación y control de subvenciones vinculadas (exclusivamente) a este Plan, sin introducir modificaciones en la LGS ni en el RGS, al menos no directamente, porque otras modificaciones que establece (como las referidas a los convenios de colaboración) sí pueden afectar significativamente pro futuro a la gestión de subvenciones articuladas de este modo. Entre las singularidades previstas para la gestión de subvenciones financiadas con cargo a este plan y estos fondos se contempla la acumulación de bases y convocatorias, la omisión del deber de acreditar las circunstancias que legitiman la concesión directa, la elevación del importe para acreditar estar al corriente de obligaciones tributarias y con la Seguridad Social, así como de los umbrales para acreditar la subvenciones mediante cuenta justificativa, la flexibilización de la tramitación anticipada de subvenciones, de la transferencia a las Comunidades Autónomas de las llamadas subvenciones gestionadas y de la concesión de subvenciones en régimen de concurrencia, así como una sustitución generalizada de los sistemas de fiscalización previa por controles financieros posteriores.

${ }_{23}$ El apartado 1 de la DA 3. ${ }^{\text {a }}$ del Real Decreto 463/2020 dispuso que: «Se suspenden términos y se interrumpen los plazos para la tramitación de los procedimientos de las entidades del sector público. El cómputo de los plazos se reanudará en el momento en que pierda vigencia el presente real decreto o, en su caso, las prórrogas del mismo». 
de los servicios». Y parece obvio que tales circunstancias podían fácilmente concurrir en el ámbito subvencional, tanto para establecer líneas de subvenciones en ámbitos de emergencia social y económica de ciertos sectores, como para continuar con la tramitación de las convocatorias abiertas. En tales supuestos, a mi juicio, exigencias como la «conformidad» de los interesados para ordenar la continuación de los procedimientos subvencionales abiertos resultaban absurdas y poco operativas en aquellos momentos iniciales de la crisis sanitaria.

A lo anterior hay que añadir que la IGAE, a través de la BDNS, publicó en abril de 2020 un dossier de preguntas frecuentes (FAQ) referidas a la incidencia del estado de alarma en la Base de Datos Nacional de Subvenciones (BDNS) y en el Sistema Nacional de Publicidad de las Subvenciones concedidas por Administraciones Públicas (SNPSAP), que ayudó «informalmente» a resolver algunas incertidumbres sobre la gestión de subvenciones. Así, se sugería que, en vez de publicar un anuncio de suspensión de los términos y plazos en dichas plataformas, para no colapsar además la publicación en diarios oficiales, "como buena práctica se recomienda insertar en la sección de subvenciones y ayudas de la página web del órgano convocante un mensaje o una ventana informativa». Asimismo, la IGAE manifestó que si bien la suspensión de los procedimientos administrativos «no ha alterado la obligación de registro en la BDNS [...]. Dada la especial situación surgida durante el estado de alarma, se pueda posponer dicho registro a un momento posterior» ${ }^{24}$. Por otra parte, respecto de la admisión de solicitudes presentadas durante el estado de alarma, la IGAE consideró que resultaba admisible dicha presentación si el solicitante podía cumplimentarla vía telemática, pero advertía que «en el caso de convocatorias de concurrencia competitiva, la resolución de concesión deberá contemplar todas las solicitudes recibidas, incluso las que se presenten una vez que haya concluido el periodo de suspensión establecido durante el estado de alarma».

Ninguna previsión se establecía, en cambio, respecto de los Planes Estratégicos de Subvenciones en la medida en que las nuevas líneas de subvenciones no tuvieran cabida en el mismo, lo que fácilmente podía suceder con las vinculadas a actividades económicas y de servicios (hostelería, comercio, turismo, ocio...), dado que en un contexto de normalidad no se trataba de ámbitos habitualmente subvencionables por las entidades locales. A mi juicio, hay que tener en cuenta como ha señalado el Tribunal Supremo, que los planes estratégicos de subvenciones, si bien tienen carácter previo al establecimiento de cualquier subvención y constituyen un requisito esencial cuyo cumplimiento exige que sea formalizado externamente y con un contenido que le haga identificable como tal por reflejar el contenido que exige el art. 8 LGS, no siendo equiparable a la mera inclusión en el presupuesto municipal de una partida destinada a hacer efectivas las ayudas de que se trata, no son sino «instrumentos de gestión de carácter programático que carecen de rango normativo» de modo que ninguna invalidez sustancial cabría imputar a la convoca-

24 Disponible en https://www.oficinavirtual.pap.hacienda.gob.es/sitios/oficinavirtualles-ES/CatalogoSistemasInformacion/TESEOnet/Documents/Actualizaci\%C3\%B3n\%20FAQ\%20BDNS\%20Estado\%20de\%20alarma. pdf(consultada el 18 de marzo de 2021). 
toria de subvenciones vinculadas a la covid-19 no previstas en los PES. A fin de cuentas, se trata de una exigencia, como señalamos anteriormente, desproporcionada para muchas entidades locales, y con una virtualidad limitada al ámbito interno del ayuntamiento, útil desde luego para transparentar la política subvencional, pero irrelevante para los potenciales beneficiarios, pues de los PES no se infieren derechos ni obligaciones ${ }^{25}$.

En todo caso, como sucedió con toda la normativa pandémica, aprobada de forma improvisada y precipitada a medida que avanzaba la situación, parecía oportuno una regulación singularizada de los procedimientos subvencionales, y a tal efecto, el art. 54 del Real Decreto-ley 11/2020, de 31 de marzo, por el que se adoptan medidas urgentes complementarias en el ámbito social y económico para hacer frente a la covid-19, dispuso, como medidas especiales en materia de subvenciones y ayudas públicas, lo siguiente:

"Art. 54. Medidas en materia de subvenciones y ayudas públicas.

1. En los procedimientos de concesión de subvenciones, las órdenes y resoluciones de convocatoria y concesión de subvenciones y ayudas públicas previstas en el art. 22.1 de la Ley 38/2003, de 17 de noviembre, General de Subvenciones, que ya hubieran sido otorgadas en el momento de la entrada en vigor del Real Decreto 463/2020, podrán ser modificadas para ampliar los plazos de ejecución de la actividad subvencionada y, en su caso, de justificación y comprobación de dicha ejecución, aunque no se hubiera contemplado en las correspondientes bases reguladoras.

A estos efectos, el órgano competente deberá justificar únicamente la imposibilidad de realizar la actividad subvencionada durante la vigencia del estado de alarma, así como la insuficiencia del plazo que reste tras su finalización para la realización de la actividad subvencionada o su justificación o comprobación.

2. También podrán ser modificadas, a instancia del beneficiario, las resoluciones y convenios de concesión de subvenciones previstas en el art. 22.2 de la Ley 38/2003, de 17 de noviembre, General de Subvenciones, sin necesidad de que sea modificado, en su caso, el real decreto previsto en el art. 28.2 de dicha ley, en las mismas condiciones y con los mismos requisitos previstos en el apartado anterior. No obstante, en el caso de que el objeto de la subvención sea la financiación de los gastos de funcionamiento de una entidad, el plazo de ejecución establecido inicialmente no podrá ser modificado.

3. La adopción de estas modificaciones no está sujeta a los requisitos previstos en el apartado 4 de la DA 3. ${ }^{a}$ del Real Decreto 463/2020 y no afecta a la suspensión de los plazos establecida en el apartado 1 de la mencionada disposición adicional».

Varias observaciones merece esta regulación especial y singularizada del procedimiento subvencional.

La primera es que la posibilidad de conceder ampliaciones de los plazos de ejecución de la actividad subvencionada y, en su caso, de justificación y comprobación de dicha ejecución, se admitía - incluso aunque no estuviera previa en las bases reguladoras«únicamente» por decisión motivada del órgano competente de la subvención en los supuestos de concesión en régimen de concurrencia o, a petición del beneficiario, en los

25 Vid., entre otras, SSTS de 16 de junio y de 4 de diciembre de 2012, y de 16 de abril de 2013. 
supuestos de concesión directa. Sin embargo, a mi juicio, incluso en los supuestos de concurrencia competitiva, nada impedía atender también a la solicitud que pudiera formular el beneficiario acreditando circunstancias objetivas de la imposibilidad de ejecutar o justificar la subvención, solicitud que podía formularse bien al amparo del régimen general (art. 32.3 LPAC), bien al amparo del art. 70.2 RGS, siempre y cuando, claro está, el plazo de ejecución o justificación no hubiera vencido ya antes de la declaración del estado de alarma ${ }^{26}$. Lo que la norma no precisaba era qué órgano debía acordar esa ampliación (el convocante, esto es, en el ámbito local, el Pleno o la Junta de Gobierno local o el gestor,) ni cuál era el límite o referencia temporal para acordar esa ampliación de plazo. En mi opinión, la primera incertidumbre debía responderse en atención al caso singularizado, y, con relación a la segunda, cabía admitir cualquier decisión motivada del órgano competente que, ponderadas las excepcionales circunstancias, así como la naturaleza de la actividad subvencionada o los requisitos de su justificación, resultara acorde y proporcionada y no desvirtuara el régimen jurídico sustantivo de la subvención.

En el ámbito de la justificación y posterior comprobación de subvenciones, teniendo en cuenta que existe un plazo cierto para aquella (el previsto en las bases reguladoras y, en su defecto, tres meses ex art. 30.2 LGS), pero no un plazo cierto para la comprobación de esa justificación (art. 32 LGS), procede recordar dos observaciones recientes que ha señalado el Tribunal Supremo al respecto. En primer lugar, que «no cabe mezclar lo que son dos actuaciones administrativas distintas y sujetas a unos requerimientos temporales diferentes: por una parte, la verificación de la justificación presentada por el beneficiario y, por otra, la comprobación de la actuación comprometida. Son dos actuaciones distintas no solo porque así las enuncia el art. 32 LGS, sino porque tienen finalidades y ámbitos de actuación diversos. La primera, la verificación o comprobación de la justificación, es de naturaleza formal y está destinada a contrastar la completitud de la justificación presentada, como paso previo a autorizar el pago. Por ello debe desarrollarse en un plazo breve, atendido su limitado ámbito de comprobación. La segunda, de comprobación de la actividad o adopción del comportamiento para el que se otorgó la subvención puede tener un alcance mucho más amplio y por ello perdura en tanto no prescriba la acción de reintegro (art. 39.1 LGS). Por tanto, la verificación o, como dice el art. 32.1 LGS, la comprobación de la justificación, por una parte, y la comprobación de la realización de la actividad y cumplimiento de la finalidad que determinó la conce-

26 Interesa destacar que si bien la demora en la ejecución y justificación de la actividad subvencional puede ponderarse en atención al grado de ejecución de la actividad subvencionada o las circunstancias concurrentes a los efectos de incorporar el principio de proporcionalidad a los reintegros exigidos por estas causas, el Tribunal Supremo ha señalado que el referido principio «no puede aplicarse con total laxitud, sino que se deben establecer previo a su aplicación una serie de criterios objetivos que sirvan para clarificar la interpretación de las normas jurídicas aplicables, de acuerdo a los principios de seguridad jurídica e igualdad, considerándose como regla general que el incumplimiento —o cumplimiento parcial— de las obligaciones contraídas comportará la caducidad de los beneficios y la devolución de los percibidos, admitiéndose única y exclusivamente la modulación de tal efecto devolutivo solo en aquellos casos en los que el cumplimiento de las obligaciones se aproxima de modo significativo al cumplimiento total, acreditando, además, el subvencionado una actuación inequívocamente tendente a la satisfacción de sus compromisos», vid. STS de 8 de mayo de 2017, rec. núm. 4146/2014. 
sión o disfrute de la subvención, por otra, son actividades administrativas distintas, que no están sujetas a un régimen temporal común». Así pues, la ampliación del plazo para presentar la justificación de subvenciones que debiera haberse cumplido a partir del 14 de marzo podía haberse ampliado, de oficio o a instancia del beneficiario, en el periodo que motivadamente hubiera acordado el órgano competente a la vista de las consideraciones formuladas, en su caso, por el beneficiario. Y con relación al plazo para efectuar la comprobación de esa cuenta justificativa podía considerarse ampliado durante el tiempo «paralizado» (esto es, por setenta y ocho días, que resultaría del plazo comprendido entre el 14 de marzo y el 1 de junio), periodo que solamente hubiera sido materialmente relevante de estar próxima la prescripción para ejercer la acción de reintegro, pues, conforme ha señalado el Tribunal Supremo, para efectuar la comprobación de la justificación de la subvención por el órgano gestor - a diferencia de lo que sucede cuando formalmente se ha iniciado un procedimiento de control financiero- no existe otro límite temporal que el plazo de prescripción de la potestad de exigir el reintegro ${ }^{27}$. Es más, y en segundo lugar, procede recordar que el Tribunal Supremo ha precisado que "la verificación y comprobación desplegada por la Administración pública de una subvención concedida que culmina con la liquidación del importe y abono de la ayuda, no enerva, anula o elimina la posibilidad de incoar un procedimiento de reintegro, ni aboca al procedimiento de revisión de oficio, pues la naturaleza jurídica de tal liquidación y abono no es la de una resolución que, de manera definitiva y firme, reconozca al beneficiario el derecho a percibir la subvención en la cuantía que se liquida y abona, sino la de una liquidación y pago provisionales, sujetos, en su caso, a lo que resulte de comprobaciones ulteriores culminadas dentro del plazo de prescripción de cuatro años que establece el art. $39.1 \mathrm{de}$ la Ley General de Subvenciones» ${ }^{28}$.

En cambio, tratándose de un procedimiento de control financiero de subvenciones iniciado antes del 14 de marzo de 2020, sometido a un plazo general de doce meses en la normativa estatal - sin perjuicio de las salvedades que contiene la LGS en materia de control financiero de subvenciones en su DA 14-, cabe entender que el órgano de control interno podía proponer motivadamente la ampliación del plazo en los términos ya señalados, aunque, ciertamente, para la gran mayoría de subvenciones de entidades locales - la mayoría de los cuales aún no tienen implantado un régimen de control financiero de subvenciones - dicho plazo resulta excesivamente largo.

27 En la práctica, no obstante, en condiciones de normalidad, usualmente el plazo de comprobación de la justificación tendrá como límite el año del ejercicio en el que se presente la misma a los efectos de dar cumplimiento a la imputación temporal del art. 176 LRHL y el art. 21 del Real Decreto 500/1990.

28 Vid. STS de 14 de enero de 2020, rec. núm. 4926/2017. Procede apuntar asimismo que el Tribunal Supremo ha legitimado la posibilidad de reiterar comprobaciones sobre la misma subvención señalando que «la verificación y comprobación desplegada por la Administración pública de una subvención concedida que culmina con la liquidación del importe y abono de la ayuda no impide posteriores comprobaciones, y no necesita del inicio del procedimiento de control financiero sometido al régimen jurídico previsto en los arts. 49 a 51 LGS, para que puedan tener lugar nuevas actuaciones de comprobación de la subvención ya liquidada y derivar en un expediente de reintegro, actuaciones de comprobación que pueden realizarse por el órgano concedente de la ayuda al amparo del art. 32 LGS», vid. STS de 25 de mayo de 2020, rec. núm. 1604/2019. 
Por otro lado, debe observarse también que tal medida no se limitó a subvenciones vinculadas o relacionadas con el estado de alarma (esto es, ayudas de carácter social y referidas a sectores económicos especialmente afectados por la crisis), sino que resultaba de aplicación a cualquier otro tipo de subvención municipal en fase de ejecución, justificación o comprobación a partir de la declaración del estado de alarma del 14 de marzo de 2020 .

En todo caso, las entidades locales no han sido ajenas a las especiales circunstancias que pudieran haber dificultado la ejecución y justificación de las actividades subvencionadas $y$, sin tener datos ciertos al respecto, no parece que hayan interpretado restrictivamente las posibilidades de ampliación de plazos de ejecución y justificación de las actividades subvencionadas. De hecho, en algún caso se ha previsto normativamente incluso que la imposibilidad de cumplir el plazo para la ejecución del proyecto subvencionado o de ejecutarlo totalmente «no se consideren como incumplimiento, a los efectos de reintegro o pérdida del derecho a la subvención» ${ }^{29}$.

Una segunda observación procedimental que procede apuntar guarda relación con las formas de conceder subvenciones. Al respecto, como se indicó anteriormente, la DA 14 de la LGS prevé la adaptación reglamentaria de los procedimientos establecidos en la ley respecto de las subvenciones concedidas por las entidades locales. Dado que en este punto concurren competencias estatales y autonómicas, lo cierto es que en la actualidad no existe un marco procedimental común aplicable a todas las entidades locales, aunque esta ausencia de parámetro no supone un problema en tanto que si bien el art. 22 LGS - que establece los procedimientos de concesión- no tiene carácter básico, sí lo tiene el art. 8 LGS, que establece como principios generales para el establecimiento (y también para la concesión) la concurrencia, objetividad, igualdad y no discriminación. Tales exigencias conducen, en definitiva, a acudir a la concesión en régimen de concurrencia competitiva como regla general de otorgamiento de subvenciones públicas, siendo la concesión directa una posibilidad que debe considerarse excepcional y solamente cuando se acrediten circunstancias objetivas debidamente justificadas que impidan acudir a la concesión concurrencial. En particular, conforme al citado art. 22.2 LGTS solamente:

«Podrán concederse de forma directa las siguientes subvenciones:

a) Las previstas nominativamente en los Presupuestos Generales del Estado, de las Comunidades Autónomas o de las entidades locales, en los términos recogidos en los convenios y en la normativa reguladora de estas subvenciones ${ }^{30}$.

29 Vid., a título de ejemplo, el art. 5 del Decreto-ley 4/2020, de 20 de marzo, por el que se establecen medidas urgentes en materia de contratación, convenios, conciertos educativos y subvenciones, servicios sociales, medio ambiente, procedimientos administrativos y presupuestarios para hacer frente al impacto económico y social de la covid-19 de las Islas Baleares.

30 La LGS precisa en este punto que «se entiende por subvención prevista nominativamente en los Presupuestos Generales del Estado aquella en que al menos su dotación presupuestaria y beneficiario aparezcan determinados en los estados de gasto del Presupuesto. El objeto de estas subvenciones deberá quedar determina- 
b) Aquellas cuyo otorgamiento o cuantía venga impuesto a la Administración por una norma de rango legal, que seguirán el procedimiento de concesión que les resulte de aplicación de acuerdo con su propia normativa.

c) Con carácter excepcional, aquellas otras subvenciones en que se acrediten razones de interés público, social, económico o humanitario, u otras debidamente justificadas que dificulten su convocatoria pública».

Pues bien, en el ámbito municipal es habitual la utilización de la concesión directa de subvenciones, con mayor intensidad cuanto más pequeña sea la entidad local. Por ello no puede extrañar que, sobre todo en entidades locales inferiores a 20.000 habitantes, se haya acudido a la concesión directa de subvenciones identificando a los beneficiarios o a la concesión en régimen de concurrencia no competitiva con convocatorias abiertas sin limitaciones presupuestarias al objeto de atender las demandas y solicitudes de los beneficiarios según evolucionaba la situación pandémica en el municipio. Por supuesto, nada hay que objetar, a mi juicio, en esta operatoria siempre y cuando el contexto de emergencia no fuera utilizado para desvirtuar injustificada o arbitrariamente la concesión directa de subvenciones que, aun en situaciones de emergencia sanitaria, sigue teniendo legalmente un carácter excepcional.

Mención especial merecen las subvenciones amparadas o articuladas vía convenios de colaboración. Esta fórmula está contemplada en la ley para canalizar las subvenciones previstas nominativamente en los respectivos presupuestos (art. 28.1 LGS), y también es la empleada para ordenar las otras dos posibilidades de concesión directa de subvenciones (subvenciones impuestas por una norma de origen legal y subvenciones por razones de interés público, social, económico o humanitario), en tanto que el convenio permite identificar las obligaciones, condiciones de los gastos subvencionables, plazos de ejecución y justificación de los beneficiarios, a modo de bases reguladoras ad hoc. Así se contempla expresamente en el art. 48.7 LRJSP al disponer que "cuando el convenio instrumente una subvención deberá cumplir con lo previsto en la Ley 38/2003, de 17 de noviembre, General de Subvenciones, y en la normativa autonómica de desarrollo que, en su caso, resulte aplicable». Ahora bien, como es sabido, existe otra práctica convencional que no se emplea formalmente como vehículo de verdadera colaboración (con obligaciones y compromisos recíprocos y satisfacción de intereses comunes respectivos), sino con el único objeto de amparar una concesión directa de subvenciones (o un verdadero contrato en otros casos). No procede ahora analizar esta controvertida cuestión y práctica administrativa ${ }^{31}$, baste señalar, a los efectos del objetivo de este trabajo, que en

do expresamente en el correspondiente convenio de colaboración o resolución de concesión que, en todo caso, deberá ser congruente con la clasificación funcional y económica del correspondiente crédito presupuestario».

31 Es clásica, a estos efectos, la crítica del Tribunal de Cuentas acerca del abuso de la técnica convencional para encubrir subvenciones y contratos, vid. Moción a las Cortes Generales sobre la necesidad de establecer un adecuado marco legal para el empleo del convenio de colaboración por las Administraciones públicas de 30 de noviembre de 2010. Que estamos ante una práctica controvertida e ilegal, en muchos casos, ha sido puesto de manifiesto por la doctrina. Vid., entre otros, A. HuERGO LORA, Los contratos sobre los actos y las potestades administrativas, Civitas, Madrid, 1998; G. FernÁndeZ FARrerES, "Subvenciones y ayudas económicas en 
el contexto de la covid-19 no se aprecia que haya variado en uno u otro sentido este modus operandi de algunas administraciones. No obstante, por aplicación de la regla especial establecida en el citado art. 54.2 del Real Decreto-ley 11/2020 procede señalar que si bien se autorizó la modificación, «a instancias del beneficiario» de las resoluciones y convenios de concesión de subvenciones directas, sin necesidad de que fuera modificada la norma habilitante (real decreto en el ámbito estatal), a los efectos de ampliar los plazos de ejecución, justificación y comprobación de la actividad subvencionada, se incluyó la cautela de que «en el caso de que el objeto de la subvención sea la financiación de los gastos de funcionamiento de una entidad, el plazo de ejecución establecido inicialmente no podrá ser modificado».

A modo de conclusión procede señalar que las entidades locales han ejercido ampliamente su potestad subvencional desde la declaración del primer estado de alarma en dos grandes ámbitos: la asistencia y ayuda social en situaciones de emergencia, competencia propia de las entidades locales, y la protección de actividades y sectores económicos especialmente afectados por la crisis (hostelería, comercio, turismo), competencia municipal más dudosa donde, junto a las subvenciones directas, se han empleado también las dirigidas a compensar el pago de tributos locales. La tramitación procedimental de las subvenciones por las entidades locales se ha visto igualmente afectada por la crisis sanitaria. En este punto, la ampliación de los plazos para la ejecución, justificación y comprobación de la actividad subvencionada ha sido la singularidad procedimental más relevante, aparte de la flexibilización y agilización de trámites y del pago anticipado del importe total de la subvención en determinados supuestos.

tiempos de crisis», op. cit., p. 127; F. J. BAUZÁ MARTORELL, "Convenios con particulares: límites entre contrato, convenio y subvención», Revista General de Derecho Administrativo, núm. 48, 2018. 
